\title{
Burnout and its Associated Factors in Medical Students of Lahore, Pakistan
}

Yumna Muzafar ${ }^{1}$, Hibbah H. Khan ${ }^{1}$, Huma Ashraf ${ }^{1}$, Waqas Hussain ${ }^{1}$, Hifsa Sajid ${ }^{1}$, Marium Tahir $^{1}$, Abdul Rehman ${ }^{2}$, Aleena Sohail ${ }^{2}$, Ahmed Waqas ${ }^{3}$, Waqas Ahmad ${ }^{1}$

1. Medical Student, CMH Lahore Medical College and Institute of Dentistry, Lahore Cantt, Pakistan 2. Medical Student, Allama Iqbal Medical College, Lahore, Pakistan 3. Department of Psychiatry, CMH Lahore Medical College and Institute of Dentistry

$\square$ Corresponding author: Waqas Ahmad,waqas_lalamusa@yahoo.com Disclosures can be found in Additional Information at the end of the article

\section{Abstract}

Introduction:

Burnout is a widely known phenomenon. It is defined as a state of prolonged physical and psychological exhaustion and is experienced virtually by every medical student due to the highly demanding nature of medical education. This study probes into the prevalence and psychosocial determinants of burnout in Pakistani medical students.

Methods:

A descriptive, cross-sectional study design and convenience (non-probability) sampling technique were employed in undergraduate medical students from years 1-5. A total of 777 medical students from two medical colleges were included in the study from May-August, 2014. An English version of the Copenhagen Burnout Inventory (CBI) and a series of demographic questions, intermixed with questions from other topics, were included in the questionnaire. Data was analysed by using SPSS ver.21.

Results:

The majority of students were females and enrolled in the third year of MBBS. Of the medical students involved, 30.6\% were found to have high/very high levels of burnout (Kristenson's burnout scoring). Although $38.7 \%$ of students said that they did not feel burned out after reading the definition of burnout given in the questionnaire, $35.9 \%$ out of these students actually had high levels of burnout according to CBI. According to the multiple regression analysis, burnout in medical students was significantly associated with age, gender, doctor parents, no help or no supportive resources (e.g., from colleagues), lack of time off, lack of belief in what you do, fear of big consequences of failure, family responsibilities, and uncertain future. Perception of teachers lacking leadership skills and doing too much study with little balance was associated with low burnout scores.

Conclusion:

There is a high prevalence of burnout in Pakistani medical students. The present study identifies several factors associated with burnout in Pakistani medical students. Although these factors are a part of daily life of medical students, their identification should prompt the use of effective coping strategies and skills, thus, minimising their burnout levels. 
Categories: Medical Education, Psychiatry, Miscellaneous

Keywords: medical students, burnout, lahore, associated factors, pakistan, Academic Performance

\section{Introduction}

In the fast-paced, competitive world of today, many people consider stress to be a part of life. Increasingly high demands of the educational system on students mean that they, too, are not immune to emotional strain and anxiety. Undergraduate medical education, in particular, is notorious for being long and emotionally taxing. Medical students often encounter intense and demanding circumstances in the course of their academic studies. This leads to reports of high levels of stress and psychiatric morbidity in them, including, but not limited to, depression and GAD (General Anxiety Disorders) [1-3]. In a cross-sectional questionnaire-based study conducted at Surat Medical College, Pakistan in 2012 by Solanky, et al., almost all the medical students reported stressor experiences of which $40 \%$ were severe in nature while another study conducted in found nearly half the students in medical school to be anxious and/or depressed [2-3]. Given these taxing circumstances, it is only predictable that at some point a large number of these students would be burnt-out.

First coined in the 1970s by the American psychologist Herbert Freudenberger, the term "burnout" is broadly described as a state of chronic stress leading to physical and emotional exhaustion, cynicism, detachment, feelings of inadequacy, and lack of accomplishment [4]. Despite the existence of multiple similar definitions, no single interpretation has been agreed upon so far. Freudenberger defined burnout as "the extinction of motivation or incentive, especially where one's devotion to a cause or relationship fails to produce the desired results" and used it to describe the consequences of severe stress and high standards experienced by people working in "helping" professions, such as doctors and nurses, who aid others at a cost to themselves [5]. Today, however, "burnout" has become a popular term and is used not only for illustrating the dark side of self-sacrifice but rather as a disorder that seems to affect anyone, from stressed-out professionals, students, and celebrities to over-burdened employees and homemakers. Despite this popularity, burnout is not yet recognized as a psychiatric disorder in its own right in the DSM-5 (Diagnostic and Statistical Manual of Mental Disorders, 5th Edition). This lack of universal acceptance means that many do not believe in burnout as a primary diagnosis due to its close resemblance to depressive disorders and alleged ambiguity in the inventories currently used for assessing burnout in individuals [6-7].

A study published in 2014 based on a national survey carried out in the US found that medical students, residents/fellows, and physicians with less than five years' practice were more likely to be burnt-out compared to the general population [8]. A 2013 literature review by Ishak, et al. revealed that burnout is prevalent during medical school, with major US multi-institutional studies estimating that at least half of all medical students may be affected by burnout during their medical education. Further, it illustrated that burnout may persist beyond medical school and is, at times, associated with psychiatric disorders and suicidal ideation [9].

Over the years, quite a few studies have attempted to pinpoint the factors that lead to burnout. An assessment of burnout in British medical students revealed that the year of study, physical activity, and smoking status significantly predicted the emotional exhaustion component of the burnout inventory whilst gender, year of study, and institution significantly predicted depersonalization. Alcohol binge score, year of study, gender, and physical activity significantly predicted personal accomplishment [10]. Another study tested the connection between burnout and personality type, demonstrating that impulsivity trait is associated with high levels of burnout with neuroticism and Type-A behavior also showing some association. Apart from these, depressive symptoms and financial concerns in the first year also displayed high association with burnout in later years [1]. Yet another study found the prevalence of burnout 
to be higher among those who did not have confidence in their clinical skills, those who felt uncomfortable with course activities, and those who did not see the coursework as a source of pleasure [11]. The effect of gender on the possibility of burnout is rather ambiguous with literature that shows equal rates of burnout in both genders and literature that demonstrates higher rates of burnout in females, although the general stress levels are found to be higher in females compared to males [12-13]. Also related to the risk of burnout are recent negative events in a students' personal life [14].

The goal of imparting medical education is to produce knowledgeable, skillful, and professional physicians. As is evident, however, students' mental and emotional health is adversely affected in medical school, which results in both personal and professional deterioration including, but not limited to substance abuse, relationship problems, suicidal ideation, worsening relationship with faculty and lack of empathy and professionalism [15-16].

Medical students worldwide encounter tremendously challenging conditions and feelings of inadequacy, which are understandable in a field that deals with human life. The cultural and social dynamics of Pakistan create unique stresses in their lives. This study probes into the determinants and prevalence of burnout in Pakistani medical students, which is a subject that has not, to our knowledge, been adequately scrutinized previously.

\section{Materials And Methods}

\section{Study design}

Descriptive, cross-sectional study design and convenience (non-probability) sampling technique was employed. In Pakistan, undergraduate medical education lasts five years. This includes two pre-clinical years and three clinical years. The prevalence of burnout in medical students of academic year one to five from two medical colleges, a government college (Services Institute of Medical Sciences, SIMS) and a private college (CMH Lahore Medical College), were assessed between May 2014 and August 2014. The English version of the Copenhagen Burnout Inventory (CBI) and a series of demographic questions were included in the questionnaire. The minimum sample size required for the present study was calculated as 384 with a $95 \%$ confidence level and a confidence interval of five.

\section{Ethics statement}

The CMH Lahore Medical College and Institute of Dentistry Ethics Review Committee approved the study. Participants who agreed to participate were explained the nature and the objectives of the study, and informed consent was obtained.

\section{Instrument}

The Copenhagen Burnout Inventory was employed, which measures three aspects of burnout in respondents' lives: personal, work-related, and patient-related. The present study assesses only the personal aspects of burnout, thus, employing the personal burnout scale consisting of six items. The Cronbach's alpha for the personal burnout scale is 0.87 which reflects a good internal consistency of this scale. All burnout items were intermixed. In this study, responses were made in the following categories: Always, Often, Sometimes, Seldom, Never/Almost Never with each corresponding to a score $100,75,50,25,0$. Total score on the scale is the average of the scores on the items [17].

\section{Data analysis}

IBM SPSS Statistics for Windows, version 21.0 software (IBM Corp., Armonk, NY, USA) was used for analysis. Frequencies were calculated for demographic variables. Mean burnout scores were 


\section{Cureus}

calculated and divided into quartiles. They were then further recoded as a dichotomous variable (cut-off value $=50$ ). Burnout scores less than 50 were coded as low levels and $>50$ as high burnout levels.

The frequencies of stressors were grouped into dichotomies as follows: never/rarely/sometimes and often/always. Multiple regression analysis (backward method) was run to identify the significant determinants of scores on the Copenhagen Burnout Inventory. The burnout scores were used as a dependent variable and age, gender, year of study, residence, the profession of parents (doctors/ not doctors), and various stressors associated with medical school were entered as predictor variables.

\section{Results}

\section{Demographic characteristics}

A total of 777 medical students participated in the survey. Out of these, 447 (57.5\%) were female and 330 (42.5\%) were male students. Most of the students belonged to third year MBBS (266, 34.2\%) followed by first year (184, 23.7\%), second year (132, 17\%), fifth year $(105,13.5 \%)$, and fourth year $(90,11.6 \%)$. Most of the students were Pakistanis $(738,95 \%)$ while the remainder had a foreign background (39, 5\%). Almost 244 (31.4\%) of the students had physician parents. According to Kristenson's criteria of burn out levels, most of the students had low burn out levels 328 (42.2\%), nil 81 (10.4\%), moderate 123 (15.8\%), high 156 (20.1\%), and very high 89 (11.5\%) [18]. Chi-square associations of demographics and burnout levels are given in Table 1.

\section{Burnout Levels}

Low levels

Frequency (n)

\section{Gender}

Male

Female

Study year

Pre-clinical group

Clinical group

Doctor parents

Yes

No

Background

Pakistani

Foreign
$203(61.5 \%)$

206 (46.1\%)

$162(51.3 \%)$

247 (52.6\%)

128 (52.5\%)

281 (52.7\%)

395 (53.5\%)

14 (35.9\%)
High levels

Frequency (n)

$\mathrm{X}^{2}$ value

$p$-value

18.13

$<.001$

127 (38.5\%)

241 (53.9\%)

40

.56

$154(48.7 \%)$

$214(46.4 \%)$

.01

.5

116 (47.5\%)

$252(47.3 \%)$

4.6

.03

$343(46.5 \%)$

$25(64.1 \%)$

Residence

2.3 


\section{Cureus}

Off campus

On campus

Relationship

Single

Married

In a relationship

Engaged

Current rotation

Outpatient

Ward

Not applicable

Do you feel burnt out?

No

Yes
209 (50.1\%)

200 (55.6\%)

279 (45.2\%)

$26(52 \%)$

$41(57.7 \%)$

$22(56.4 \%)$

1.9

.38

49 (52.1\%)

$165(45 \%)$

$154(48.7 \%)$

$162(51.3 \%)$

25.97

$<.001$

108 (35.9\%)

260 (54.6\%)

TABLE 1: Association between demographics of students and burn out levels $(n=777)$

Chi-square $=\mathrm{X}^{2}$

According to the Chi-square analysis, day scholars, female gender, and students with a foreign background reported a higher incidence of burnout. After giving the definition of burnout, "burnout is a state of prolonged physical and psychological exhaustion"[17], students were asked "Do you feel burnt out?". Out of 777 students, 301 (38.7\%) students reported negatively to the question and $35.9 \%$ (108/301) of these students, in fact, had high levels of burnout on CBI $(\mathrm{p}<0.01)$.

\section{Stressors}

Stressors most frequently cited by the respondents were: too much study with little balance, lack of time for recreation, lack of sleep, lack of time off, high frequency of tests, fear of failure, insufficient rewards of acknowledgment of your work, sense of never ending competition, scoring lower than hoped for, and high parental expectations. Detailed results are given in Table 2. 


\section{Cureus}

\begin{tabular}{|c|c|c|}
\hline Stressors & Rare (Percentage) & Frequent (Percentage) \\
\hline Too much study with little balance & $453(58.30)$ & $324(41.70)$ \\
\hline No supportive colleagues & $529(68.08)$ & $248(31.92)$ \\
\hline Too little social support & $540(69.50)$ & $237(30.50)$ \\
\hline Lack of time for recreation & $455(58.56)$ & $322(41.44)$ \\
\hline Lack of sleep & 458 (58.94) & $319(41.06)$ \\
\hline Lack of time off & $426(54.83)$ & $351(45.17)$ \\
\hline Lack of supportive relationships & $530(68.21)$ & 247 (31.79) \\
\hline Accommodation away from home & $538(69.24)$ & $239(30.76)$ \\
\hline Lack of belief in what you do & $581(74.77)$ & $196(25.23)$ \\
\hline Choosing field of medicine against your interest or family pressure & 596 (76.71) & $181(23.29)$ \\
\hline High frequency of tests & $416(53.54)$ & $361(46.46)$ \\
\hline Fear of failure & 475 (61.13) & $302(38.87)$ \\
\hline Insufficient rewards of acknowledgment of your work & $447(57.53)$ & $330(42.47)$ \\
\hline Poor communication with colleagues and teachers & $511(65.77)$ & $266(34.23)$ \\
\hline Poor leadership skills of teachers & $521(67.05)$ & 256 (32.95) \\
\hline Gender discrimination in college & $616(79.28)$ & $161(20.72)$ \\
\hline Discrimination based on social role (wife, guardian of household) & $636(81.85)$ & 141 (18.15) \\
\hline Discrimination based on caste & $672(86.49)$ & 105 (13.51) \\
\hline Sense of never ending competition & $473(60.88)$ & 304 (39.12) \\
\hline Scoring lower than hoped for & $472(60.75)$ & $305(39.25)$ \\
\hline Family responsibilities & 592 (76.19) & $185(23.81)$ \\
\hline Uncertain future & $534(68.73)$ & $243(31.27)$ \\
\hline Loss of loved one in past 12 months & $650(83.66)$ & 127 (16.34) \\
\hline Witnessed major illness of close family member & $623(80.18)$ & 154 (19.82) \\
\hline High parental expectations & $476(61.26)$ & 301 (38.74) \\
\hline Financial constraints & 615 (79.15) & $162(20.85)$ \\
\hline
\end{tabular}

TABLE 2: Frequency of stressors as reported by the respondents $(n=777)$ 


\section{Cureus}

\section{Determinants of high burnout levels}

According to multiple regression analysis, high burnout levels were significantly associated with age, gender, physician parents, no help or no supportive resources (e.g. from colleagues), lack of time off, lack of belief in what you do, fear of the big consequences of failure, family responsibilities, and uncertain future. Students who perceived that their teachers lacked leadership skills and were doing too much study with little balance had low burn out scores. Detailed results have been presented in Table 3.

\begin{tabular}{|c|c|c|c|c|}
\hline Predictor & B & Std. error B & Beta & P-value \\
\hline (Constant) & -26.437 & 58.324 & & .650 \\
\hline Age & 4.372 & 2.356 & .062 & .064 \\
\hline Gender & 41.440 & 8.085 & .172 & .000 \\
\hline Doctor parents & 38.096 & 18.312 & .070 & .038 \\
\hline Too much study with little balance & 21.333 & 11.085 & -.089 & .055 \\
\hline No help or no supportive resources (e.g. from colleagues) & 32.293 & 11.026 & .127 & .004 \\
\hline Lack of time off & 24.538 & 10.700 & .103 & .022 \\
\hline Lack of belief in what you do & 23.256 & 10.721 & .085 & .030 \\
\hline Fear of the big consequences of failure & 24.497 & 11.019 & .101 & .027 \\
\hline Poor leadership skills of teachers & -19.490 & 10.483 & -.077 & .063 \\
\hline Family responsibilities & 22.795 & 11.670 & .082 & .051 \\
\hline Uncertain future & 105 & 11.225 & .086 & .049 \\
\hline
\end{tabular}

TABLE 3: Multiple regression model for burn out scores $(n=777)$

ANOVA F=12.5, $\mathrm{P}<.005$, Adjusted R2=14.0, backward method

\section{Discussion}

In our study, about half the medical students (47\%) met the criteria for moderate, high, or very high levels of burnout. This matches well with several studies on levels of burnout among medical students. For instance, in a study of Swedish medical students, Dahlin, et al. found high levels of burnout in $47 \%$ of the students [1]. Similarly, Dyrbye, et al. found a burnout incidence of $45 \%$ among the medical students of Minnesota [14]. Mazurkiewicz, et al., however, reported higher levels of burnout (71\%) in third-year medical students of Mount Sinai School of Medicine, New York [19].

An interesting finding in our study was the fact that many medical students were unaware of their own burnout. Despite answering negatively to the question “Do you feel burnt out?", 36\% of the students were actually found to be suffering from high levels of burnout based on their responses to CBI. This lack of awareness is alarming since it can lead to neglect of symptoms 
and progression to greater levels of burnout. Numerous studies have identified the positive effects of self-awareness-based interventions in alleviating stress among both medical students and physicians. For instance, Shapiro, et al. found mindfulness-based stress reduction to reduce both depression and anxiety among medical students [20]. Similarly, Krasner, et al. found that self-awareness exercises among primary care physicians reduced both burnout and mood disturbance in them and improved their empathy [21]. We suggest promoting self-awareness strategies among medical students. Simply making them aware of their burnout could go a long way in enabling them to cope with it.

Our study identified numerous stressors among medical students, most of which were academic in nature. These stressors, including lack of sleep, lack of time off, high frequency of tests, fear of failure, and high parental expectations among others, correlate with those in published literature on the subject. For instance, in a study of stressors among Pakistani medical students, Shah, et al. highlighted high parental expectations, frequency of examination, worrying about the future, sleeping difficulties, and performance in periodic examinations as the common stressors, which are quite similar to the stressors of our study [22]. Similarly, Sreeramareddy, et al. found the vastness of syllabus, tests/exams, high parental expectations, and lack of time and facilities for entertainment as major stressors in undergraduate Nepalese medical students, again concurring with our results [23]. Waqas, et al. found that most of the Pakistani medical students (77\%) of their study were poor sleepers and that their lack of proper sleep contributed to high-stress levels among them, supporting our result of lack of sleep as a common stressor [24].

Age was found to be significantly associated with burnout. Older medical students (in senior medical years) were more burnt out than younger students (in junior medical years). This is in accordance with Dyrbye, et al.'s study, which shows that senior medical years are associated with greater burnout [14]. A study by Shaikh, et al. also supports our results. They found that fourth and fifth-year medical students had the greatest stress as compared to junior medical students [25].

We found female gender to be significantly associated with high burnout levels. Studies on burnout of medical students generally agree with our results. For instance, a study by Backović, et al. on final year medical students of Serbia found female students to be significantly more stressed and burnt out as compared to male students [12]. Another study by Dahlin, et al. also found female medical students to be more exhausted than their male counterparts [1]. The higher burnout among female medical students is more likely due to a higher perceived impact of stressors rather than a higher number of stressors as compared to male students. This view is in accordance with Ranjita, et al.'s study on the academic stress of college students in which female students rated negative events more often and more markedly as compared to male students showing an increased emotional response to stressors [26]. Accordingly, Backović, et al. reported that female medical students declared high-stress effects from contact with patients and autopsy more frequently than male students [12]. Thus, the stressors of medical school appear to impact female students more severely and, as a consequence, cause more frequent burnout in them.

Our study found significantly greater burnout among medical students whose parents were doctors. This finding is in agreement with Sreeramareddy, et al. (2007) who found greater stress among medical students whose parents were medical doctors [23]. One possible explanation for this is the fact that medical doctors have perfectionistic attitudes [27]. It is likely that their perfectionism extends to their parenting as well and results in increased expectations from their children. It is well-known that perfectionistic expectations of parents can lead to both increased depression and dysfunctional behaviour among their offspring [28]. Thus, the higher expectations of their parents and increased stress of meeting these expectations may be responsible for greater burnout among medical students with doctor parents. Another 
explanation for this relationship could be the hereditary nature of perfectionism. As pointed out by Soenens, et al., both maladaptive and adaptive perfectionism in parents can be transferred to their children because such parents employ greater psychological control in parenting [29]. The association of perfectionism with stress is well-known [30]. Therefore, the perfectionism of doctor parents passed down to their children could be responsible for greater burnout among such medical students.

Our study found an interesting factor associated with burnout, which is a lack of belief in the medical profession. The fact that even individuals training to become doctors do not believe in the medical profession is quite appalling. A review of medical literature shows that such doubts about the medical profession are common not only among the general population but also among physicians [31-32]. In a special report, Zuger points out that many physicians are dissatisfied with the medical profession in its current state and that this dissatisfaction is responsible for increased psychological morbidity of physicians on one hand and poor clinical management and substandard medical care on the other [32]. She goes so far as to liken the prevailing emotional climate among medical professionals to "the atmosphere surrounding a deathbed". In this context, our finding makes perfect sense. Thus, medical students harbouring doubts and dissatisfaction about their profession are more likely to experience psychological distress and burnout as compared to those who don't harbour such doubts. Ahmad, et al. found out in a study that medical students of Pakistan have the most doctor-centered attitudes in the entire globe, which could be attributed to the fact that medical students don't believe in their profession and are burnt out to the extent that they do not care for the patient's rights [33].

Another cause of burnout identified by our study is family responsibilities. The high commitment required for medical education can predictably add up with the family demands to increase stress on medical students. Both may even clash at times as found by Clark, et al.'s study according to which the stress of medical education can often cause difficulties in personal relationships [34]. In Pakistan, married medical students and those belonging to poor families are expected to support their families financially. Such medical students may find it difficult to meet the demands of medical education on the one hand and the financial and emotional support of their families on the other. Thus, the combined demands of medical education, family, and the stress arising from occasional conflicts between these demands can exhaust the students to the level that they become burnt out.

Among academic factors, lack of time off, fear of big consequences of failure, lack of help or supportive resources, and uncertain future were significantly associated with burnout among medical students of our study. As already mentioned above in the discussion of stressors, both Shah, et al. and Sreeramareddy, et al. have highlighted many of these factors as common stressors among medical students [22-23]. Dahlin, et al., in a study of Swedish medical students, cited both "worries about future competence/endurance" and "non-supportive climate" as major causes of stress among medical students [35]. Since these factors are repeatedly mentioned in literature as stressors, it is hardly surprising that they should cause burnout in medical students who are chronically exposed to these factors.

Finally, a rather surprising finding of our study was that students who perceived their teachers to have poor leadership skills had significantly less burnout. This contradicts Dahlin, et al.'s study according to which belief in pedagogical shortcomings was a significant predictor of stress [35]. A possible explanation for our result could be that by putting the blame on teachers, such students absolve themselves of responsibility for their academic performance. This could protect them from academic stress. In addition to this, we also found out that students who study a lot and have little time to engage in other activities had low levels of burnout, which at first looks paradoxical but it may be due to students learning strategies to keep themselves motivated to keep up the pace. 
The findings of our study clearly demonstrate that notoriety of medical education for its stressful nature is quite justifiable. Despite this well-known fact, few steps are taken to protect the students from stress and burnout. While reducing syllabus or examinations might decrease the quality of doctors produced and may, thus, be ill-advised, several other steps, including promotion of stress-reduction techniques, can protect medical students from psychological distress [36]. Such strategies could predictably lower burnout among medical students, enabling them to fully concentrate on becoming capable physicians of the future.

The study had a few limitations, which should be considered in future research. The study was conducted in only one city; further research should use a multicentric approach. The crosssectional design of this study limits deduction about causality and temporality. Students from government and private college were not separately analysed. The English version of CBI was used rather than Urdu, which is the national language of Pakistan.

\section{Conclusions}

Our study reports that burnout is prevalent among the medical students of Pakistan. A lot of medical students and teachers are unaware of the phenomenon. It is of paramount importance that the academic staff should identify this problem, and even if it can't be completely eliminated, its negative effects should be minimised by focusing on the factors we identified to increase the productivity of medical students for better patient care.

\section{Additional Information \\ Disclosures}

Human subjects: Consent was obtained by all participants in this study. CMH Lahore Medical College and Institute of Dentistry Ethics Review Committee issued approval N/A. Animal subjects: All authors have confirmed that this study did not involve animal subjects or tissue. Conflicts of interest: In compliance with the ICMJE uniform disclosure form, all authors declare the following: Payment/services info: All authors have declared that no financial support was received from any organization for the submitted work. Financial relationships: All authors have declared that they have no financial relationships at present or within the previous three years with any organizations that might have an interest in the submitted work. Other relationships: All authors have declared that there are no other relationships or activities that could appear to have influenced the submitted work.

\section{References}

1. Dahlin ME, Runeson B: Burnout and psychiatric morbidity among medical students entering clinical training: a three year prospective questionnaire and interview-based study. BMC Med Educ. 2007, $7: 6$. Accessed: January 13, 2015: http://www.biomedcentral.com/1472-6920/7/6. 10.1186/1472-6920-7-6

2. Jadoon NA, Yaqoob R, Raza A, Shehzad MA, Zeshan SC: Anxiety and depression among medical students: a cross-sectional study. J Pak Med Assoc. 2010, 60:699-702.

3. Solanky P, Desai B, Kavishwar A, Kantharia SL: Study of psychological stress among undergraduate medical students of government medical college, Surat. Int J Med Sci Public Health. 2012, 1:38-42. 10.5455/ijmsph.2012.1.38-42

4. The Tell Tale: Signs of Burnout ... Do You Have Them? (Psychology Today) . (2013). Accessed: July 23, 2015: https://www.psychologytoday.com/blog/high-octane-women/201311/the-telltale-signs-burnout-do-you-have-them.

5. Freudenberger HJ: Staff burn-out. J Soc Issues. 1974, 30:159-65. 10.1111/j.15404560.1974.tb00706.x

6. Kaschka WP, Korczak D, Broich K: Burnout a fashionable diagnosis. Dtsch Arztebl Int. 2011, 108:781-87. 10.3238/arztebl.2011.0781

7. Occupational burnout. (2015). Accessed: Accessed: November 6, 2015: 
http://https://en.wikipedia.org/wiki/Occupational_burnout.

8. Dyrbye LN, West CP, Satele D, Boone S, Tan L, Sloan J, Shanafelt TD: Burnout among U.S. medical students, residents, and early career physicians relative to the general U.S. population. Acad Med. 2014, 89:443-51. 10.1097/ACM.0000000000000134

9. Ishak W, Nikravesh R, Lederer S, Perry R, Ogunyemi D, Bernstein C: Burnout in medical students: A systematic review. Clin Teach. 2013, 10:242-45. 10.1111/tct.12014

10. Cecil J, McHale C, Hart J, Laidlaw A: Behaviour and burnout in medical students . Med Educ Online. 2014, 19:25209. 10.3402/meo.v19.25209

11. Costa EF, Santos SA, Santos AT, Melo EV, Andrade TM: Burnout Syndrome and associated factors among medical students: a cross-sectional study. Clinics (Sao Paulo). 2012, 67:573-80. 10.6061/clinics/2012(06)05

12. Backović DV, Zivojinović JI, Maksimović J, Maksimović M: Gender differences in academic stress and burnout among medical students in final years of education. Psychiatr Danub. 2012, 24:175-81.

13. Bakker AB, Demerouti E, Schaufeli WB: Validation of the Maslach Burnout Inventory General Survey: An Internet Study. Anxiety, Stress \& Coping. 2002, 15:245-60.

10.1080/1061580021000020716

14. Dyrbye LN, Thomas MR, Huntington JL, Lawson KL, Novotny PJ, Sloan JA, Shanafelt TD: Personal life events and medical student burnout: a multicenter study . Acad Med. 2006, 81:374-84. 10.1097/00001888-200604000-00010

15. Dyrbye LN, Thomas MR, Shanafelt TD: Medical student distress: causes, consequences, and proposed solutions. Mayo Clin Proc. 2005, 80:1613-22. 10.4065/80.12.1613

16. Brazeau CMLR, Schroeder R, Rovi S, Boyd L: Relationships between medical student burnout, empathy, and professionalism climate. Acad Med. 2010, 85:S33-S36.

10.1097/ACM.0b013e3181ed4c47

17. Copenhagen Burnout Inventory Normative data from a representative Danish population on Personal Burnout Results from the PUMA* study on Personal Burnout, Work Burnout, and Client Burnout. (2004). Accessed: September 19, 2015: http://goo.gl/kscQuX.

18. Borritz M, Rugulies R, Bjorner JB, Villadsen E, Mikkelsen OA, Kristensen TS: Burnout among employees in human service work: design and baseline findings of the PUMA study. Scand J Public Health. 2006, 34:49-58. 10.1080/14034940510032275

19. Mazurkiewicz R, Korenstein D, Fallar R, Ripp J: The prevalence and correlations of medical student burnout in the pre-clinical years: A cross-sectional study. Psychol Health Med. 2012, 17:188-95. 10.1080/13548506.2011.597770

20. Shapiro SL, Schwartz GE, Bonner G: Effects of mindfulness-based stress reduction on medical and premedical students. J Behav Med. 1998, 21:581-99. 10.1023/A:1018700829825

21. Krasner MS, Epstein RM, Beckman H, Suchman AL, Chapman B, Mooney CJ, Quill TE: Association of an educational program in mindful communication with burnout, empathy, and attitudes among primary care physicians. JAMA. 2009, 302:1284-93.

10.1001/jama.2009.1384

22. Shah M, Hasan S, Malik S, Sreeramareddy CT: Perceived stress, sources and severity of stress among medical undergraduates in a Pakistani medical school. BMC Med Educ. 2010, 10:2. Accessed: May 17, 2015: http://www.biomedcentral.com/1472-6920/10/2. 10.1186/1472-6920$10-2$

23. Sreeramareddy CT, Shankar PR, Binu VS, Mukhopadhyay C, Ray B, Menezes RG: Psychological morbidity, sources of stress and coping strategies among undergraduate medical students of Nepal. BMC Med Educ. 2007, 7:26. Accessed: April 22, 2015: http://www.biomedcentral.com/1472-6920/7/26. 10.1186/1472-6920-7-26

24. Waqas A, Khan S, Sharif W, Khalid U, Ali A: Association of academic stress with sleeping difficulties in medical students of a Pakistani medical school: a cross sectional survey. PeerJ. 2015, 3:e840. Accessed: March 23, 2015: https://peerj.com/articles/840/. 10.7717/peerj.840

25. Shaikh BT, Kahloon A, Kazmi M, Khalid H, Nawaz K, Khan N, Khan S: Students, stress and coping strategies: a case of Pakistani medical school. Educ Health (Abingdon). 2004, 17:34653. 10.1080/13576280400002585

26. Misra R, McKean M: College students' academic stress and it's relation to their anxiety, time management and leisure satisfaction. Am J Health Stud. 2000, 16:41-51.

27. Peters M, King J : Perfectionism in doctors. BMJ. 2012, 344:e1674. 10.1136/bmj.e1674

28. Randolph JJ, Dykman BM: Perceptions of parenting and depression-proneness in the 
offspring: Dysfunctional attitudes as a mediating mechanism. Cognitive Ther Res. 1998, 22:377-400. 10.1023/A:1018761229824

29. Soenens B, Elliot AJ, Goossens L, Vansteenkiste M, Luyten P, Duriez B: The intergenerational transmission of perfectionism: parents' psychological control as an intervening variable. J Fam Psychol. 2005, 19:358-66. 10.1037/0893-3200.19.3.358

30. Chang EC, Watkins A, Banks KH: How adaptive and maladaptive perfectionism relate to positive and negative psychological functioning: Testing a stress-mediation model in black and white female college students. J Couns Psychol. 2004, 51:93-102. 10.1037/00220167.51.1.93

31. Irvine D: The changing relationship between the public and the medical profession. J R Soc Med. 2001, 94:162-69.

32. Zuger A: Dissatisfaction with medical practice. N Engl J Med. 2004, 350:69-75. 10.1056/NEJMsr031703

33. Ahmad W, Krupat E, Asma Y, Fatima N, Attique R, Mahmood U, Waqas A: Attitudes of medical students in Lahore, Pakistan towards the doctor-patient relationship. PeerJ. 2015, 3:e1050. Accessed: January 7, 2015: https://peerj.com/articles/1050/. . 10.7717/peerj.1050

34. Clark EJ, Reiker PP: Gender differences in relationships and stress of medical and law students. J Med Educ. 1986, 61:32-40.

35. Dahlin M, Joneborg N, Runeson B: Stress and depression among medical students: a crosssectional study. Med Educ. 2005, 39:594-604. 10.1111/j.1365-2929.2005.02176.x

36. Rosenzweig S, Reibel DK, Greeson JM, Brainard GC, Hojat M: Mindfulness-based stress reduction lowers psychological distress in medical students. Teach Learn Med. 2003, 15:8892. 10.1207/S15328015TLM1502_03 